\title{
Dimensional Relationship between Maxillary Anterior Teeth and Inter Hamular Distance
}

\author{
Shrestha $\mathrm{A}^{1^{*}}$, Mathema $\mathrm{SRB}^{2}$, Maharjan $\mathrm{SK}^{3}$, Karn $\mathrm{SL}^{4}$ \\ ${ }^{1,3,4}$ Assistant Professor, ${ }^{2}$ Professor, Department of Prosthodontic and Maxillofacial Prosthesis \\ People's Dental College and Hospital, Shorakhuttee, Kathmandu, Nepal.
}

\begin{abstract}
Introduction: Selection of anterior teeth for the fabrication of artificial denture during Prosthodontic rehabilitation is a complex process. Different authors have suggested various methods, however no single method can be used reliably to select artificial teeth. This study aims to assess dimensional relationship of maxillary anterior teeth with inter hamular distance which may assist in the artificial teeth selection.

Materials and methods: This clinical study was carried out on 95dentate subjects meeting the inclusion criteria. Prior to impression making, hamular notch was located precisely with T-burnisher and was marked with indelible pencil. Impression of maxillary arch was made using irreversible hydrocolloid impression material and casts were poured using Type III dental stone. Measurements were made directly on the cast using digital vernier caliper. The contact point widths of maxillary right and left maxillary central incisors, lateral incisors and canines were measured. The distance between the right and left hamular notch was measured. The sum of contact point widths of all maxillary anterior teeth was calculated. All the data were recorded and statistically analyzed.

Result: There is a positive correlation between combined width of maxillary anterior teeth and interhamular notch distance with Pearsons's correlation coefficient (r) 0.217 and $p$ value 0.035 which is statistically significant.

Conclusions: There is significant correlation between combined width of maxillary anterior teeth and distance between right and left hamular notch. This correlation is valuable and practicable in estimating the six maxillary anterior teeth width.
\end{abstract}

Key words: Complete dentures, Maxillary anterior teeth, Denture esthetics

\section{Introduction}

Face is the most expressive part of the human body, which determines an individual's social acceptance. Loss of teeth not only affects facial appearance but also creates psychological trauma to the person. Hence it is essential that an esthetically pleasing and functionally comfortable replacement of the missing teeth should be provided with artificial substitutes such as removable, fixed and implant supported

\section{*Corresponding Author}

Dr. Ashwin Shrestha, Assistant Professor

Department of Prosthodontics and Maxillofacial

Prosthetics, People's Dental College and Hospital

Shorakhuttee, Kathmandu, Nepal.

E-mail: ashwinshrestha1@gmail.com prosthesis. Among these different modalities of Prosthodontic rehabilitation of missing teeth, fabrication of complete denture is the common rehabilitation that is routinely done in general practice. ${ }^{1}$

Selection of anterior teeth for the fabrication of artificial denture during Prosthodontic rehabilitation is a complex process. Dimensions, shape and color of teeth are the most important factors in their selection. ${ }^{6}$ During fabrication of complete dentures, clinicians may have difficulty with selection of properly sized denture teeth. Since the patient has no teeth remaining and often no records to serve as a guide, it is necessary to make a clinical decision based upon other information or technique. ${ }^{2}$ 
There is no single universally accepted method that can be used reliably to help select artificial teeth. Different authors have suggested various intraoral landmarks such as hamular notch serves as a guide for the selection of width of maxillary anterior teeth. Hamular notches have been considered to be reliable landmarks because they are not submitted to resorptive changes after teeth extraction. ${ }^{12}$ Their position is determined by anatomical structures. Studies reveal that a close relationship exists between the morphology and dimensions of maxillary anterior teeth and those of the hard palate. ${ }^{4}$

The aim of this study is to determine the relationship between dimensions of maxillary anterior teeth and those of the hard palate. No recognizable work has yet been done on this subject on the Nepalese population. This study will be a step ahead in suggesting a reliable biometric criterion for the selection of appropriately sized maxillary anterior teeth.

\section{Materials and methods}

This cross-sectional study was conducted in Department of Prosthodontics \& Maxillofacial Prosthetics, People's Dental College \& Hospital. Ninety five subjects age between 16 to 38 years with intact anterior teeth and Angle's Class I molar relationship were selected for participation in the study. Subjects with one or more teeth missing (except the third molars), having any restorations or attrition of anterior teeth, any tooth size, discripencies, marginal periodontitis and gingival recession or had undergone orthodontic treatment were not included in the study. A written consent was obtained from each subject.

A T- burnisher was used to locate the hamular notch precisely and indelible pencil (0.1 $\mathrm{mm}$ point) was used for their demarcation. Impressions of the maxillary jaw of each subject were made using irreversible hydrocolloid. Casts were obtained by pouring the recorded impressions in dental stone. A precise caliper (0.1 mm precision) was used to measure distance between the two hamular notches (Fig. 1) and contact point widths of right and left maxillary central incisors (MCIs), lateral incisors and canines (Fig. 2) were measured on the dental cast. The hamular width (HW) was measured between the most mesial demarcation point of the left and the right hamular notch.

Data was analyzed using SPSS Version 22. Mean \pm S.D was calculated for hamular width, width of central incisor, lateral incisor, canine and combined width of maxillary anterior. Ratio of combined width of maxillary anterior teeth with hamular width was then calculated.

\section{Observations and result}

This study comprised of 95 subjects in total, out of which $23(35.30 \%)$ were males and 72 $(75.8 \%)$ were females. The minimum age of the patients was 16 years and maximum age of the patients was 38 years. Descriptive statistics for mean combine width of MCIs, LIs,Cs and HW values and the ratio sum of contact point width of MA/HW are presented.

The value of Pearsons's correlation coefficient (r) between combined width of anterior teeth and inter-hamular notch is 0.217 that means a positive correlation. This correlation is statistically significant with $\mathrm{p}$ value 0.035 .

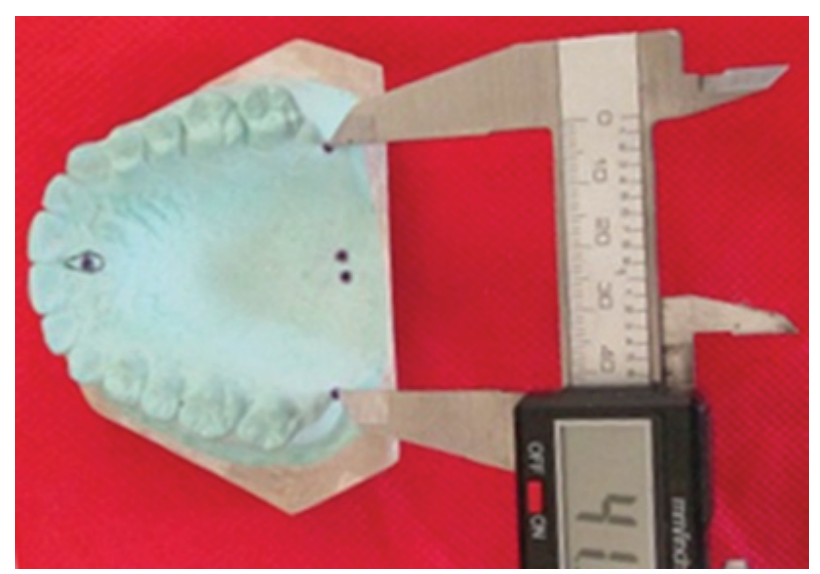

Figure 1: Measurement of inter hamular distance 


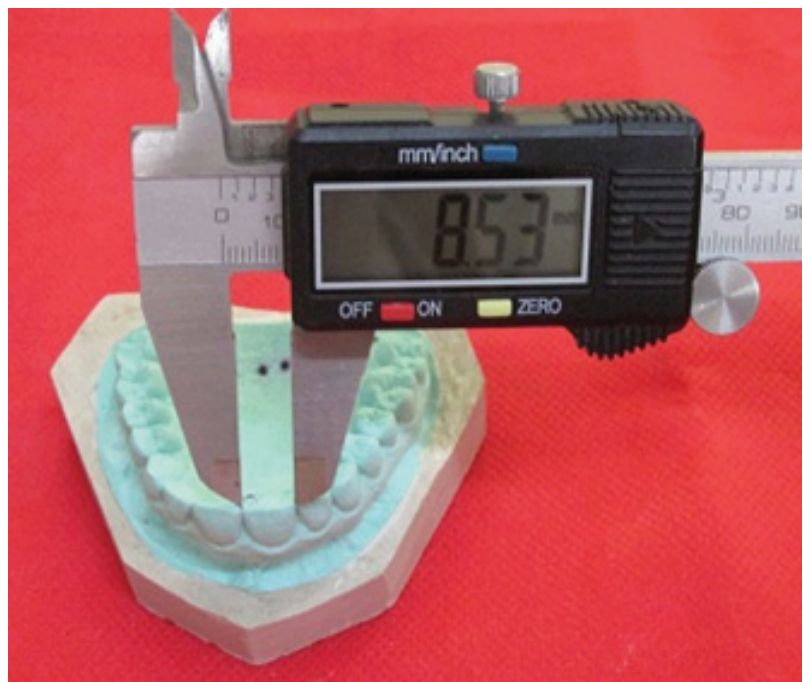

Figure 2: Measurement of width of central incisor

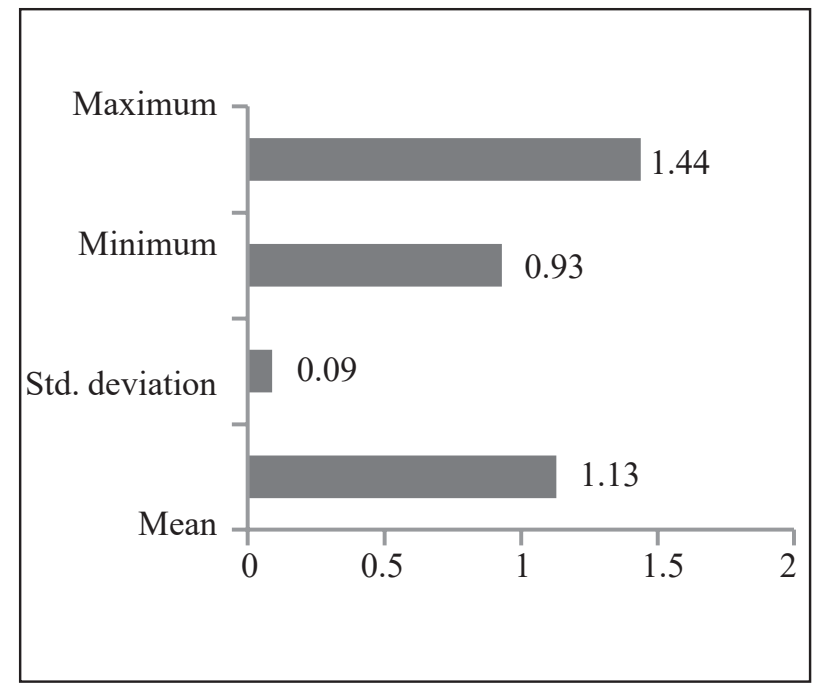

Chart 1: Descriptive statistics for ratio between sum of contact point width of all maxillary anterior teeth with inter - hamular notch distance.

Table 1: Descriptive statistics for central incisor, lateral incisor,canine widthand combined width of maxillary anterior teeth.

\begin{tabular}{|l|c|c|c|}
\hline Variables & Mean $\pm \mathbf{s d}$ & Minimum $\mathbf{( m m})$ & Maximum $(\mathbf{m m})$ \\
\hline Right Central Incisor & $8.15 \pm 0.50$ & 7.30 & 9.63 \\
\hline Left Central Incisor & $8.53 \pm 0.50$ & 7.35 & 9.84 \\
\hline Right Lateral Incisor & $6.76 \pm 0.58$ & 5.19 & 8.27 \\
\hline Left Lateral Incisor & $6.80 \pm 0.57$ & 5.44 & 8.34 \\
\hline Right Canine & $7.78 \pm 0.51$ & 6.02 & 9.12 \\
\hline Left Canine & $7.78 \pm 0.51$ & 6.43 & 9.09 \\
\hline Combined Width of MA & $46.16 \pm 2.55$ & 40.51 & 52.64 \\
\hline
\end{tabular}

Table 2: Descriptive statistics for inter - hamular notch distance

\begin{tabular}{|c|c|c|c|}
\hline Variables & Mean $\pm \mathbf{s d}$ & Minimum & Maximum \\
\hline Inter -hamular notch distance & $41.0 \pm 2.87$ & 33.44 & 48.09 \\
\hline
\end{tabular}

Table 3: Correlation between combined width of anterior teeth with inter-hamular notch distance.

\begin{tabular}{|c|c|c|c|}
\hline Correlation parameters & Correlation coefficient $(\mathbf{r})$ & Coefficient of determination $\left(\mathbf{R}^{2}\right)$ & P value \\
Combined width & 0.217 & 0.047 & $0.035^{*}$ \\
\hline
\end{tabular}

*statistically significant.

Chart 1 shows that ratio of sum of width of anterior teeth and distance between right and left hamular notch is $1.13: 1$. The range of this ratio was 0.93 to 1.44 .

\section{Discussion}

This study was conducted to assess the dimensional relationship between maxillary anterior teeth and intraoral landmarks on palate. In this study, the intraoral anatomical landmark taken into consideration was hamular notch. Hamular notches have been considered to be reliable landmarks because they are not submitted to resorptive changes after teeth extraction. ${ }^{4}$ Their position is determined by anatomical structures. Therefore inter hamular distance has been chosen as distance references in order to calculate MCI dimensions. Peticevic 
et al in 2006, Bing et al in 2009,Guldag et al in 2010, Baker et al in 2011, did same type of study and concluded that hamular notches were useful landmarks in the selection of the size of maxillary anterior teeth. ${ }^{2,4-6}$

A total of 95 sample subjects were selected in this study. The sample subjects comprised of $23(35.30 \%)$ males and $72(75.8 \%)$ females respectively, and their age ranged from1638 years. The study was conducted on young subjects ranging from $16-38$ years to avoid continuous, progressing physiological aging process that affect the natural dentition changing its morphology and appearance. ${ }^{7}$

All measurements were performed by the same operator for all the subjects in order to minimize the personal variability factors. Further, all measurements were performed directly from the casts in order to minimize other sources of error. In the similar study conducted by Zilberman et al. in 2003, it was found that measurement with digital caliper on dental stone models showed the highest accuracy and reproducibility. ${ }^{8}$

The present study showed the mean contact point width of right MCI was $8.15 \pm 0.50$ and of left MCI was $8.53 \pm 0.50 \mathrm{~mm}$. The mean values of the width of right and left lateral incisors were recorded to be $6.76 \pm 0.58$ and $6.80 \pm 0.57 \mathrm{~mm}$ respectively. The mean values of the width of right and left canines were recorded to be 7.78 \pm 0.51 and $7.78 \pm 0.51 \mathrm{~mm}$ respectively. The mean combined width of maxillary anterior six teeth was recorded to be $46.16 \pm 2.55 \mathrm{~mm}$ with minimum value of $40.51 \mathrm{~mm}$ and maximum value of $52.64 \mathrm{~mm}$.

The result obtained from this study was in agreement with study done by Petricevic et al in 2006 and Riaz et al in 2013. ${ }^{4,9}$ However the result of this study was not in agreement with the study performed by Mavroskouf et al in 1980 which reported that $86 \%$ to $90 \%$ of the subjects examined did not have identical dimensions or form of the left and right maxillary central incisors. ${ }^{10}$ In the present study the mean distance between right and left hamular notch was $41.0 \pm 2.87 \mathrm{~mm}$. The values of hamular width obtained in this study was in accordance with study conducted by Petricevic et al in 2006 and Riaz et al in 2013. ${ }^{4,9}$ Likewise, the study done by Guldag et al in 2010, who reported the mean distance of the inter pterygomaxillary notch was $42.38( \pm 3.47) \mathrm{mm}$ and by Sayed M E et al in 2017 who observed the interhamular distance to be $38.9 \mathrm{~mm} .{ }^{11,12}$

This study determined a positive correlation between combined width of maxillary anterior teeth and distance between right and left hamular notch that was statistically significant ( $p$ value - 0.035). Thus this association among SCtwMA and inte rhamular distance could be used to determine the anterior teeth width. The mean value of ratio between combined width of maxillary anterior teeth and distance between right and left hamular notch was 1.13:1 ( $\mathrm{p}>0.05)$ with a narrow range of 0.93 to $1.44 \mathrm{~mm}$.

There was no significant difference between inter hamular distance and combined width of maxillary anterior teeth. ${ }^{13}$ However study done by Guldag et al in 2010 was not in agreement with result of present study and found that the relationship between the measurements of the total mesiodistal width of the six maxillary anterior teeth and the distance between pterygomaxillary notches was not high enough to be used as a predictive factor for anterior tooth selection. ${ }^{6}$

The results of this study suggest that a statistical significant correlation exists between interhamular notch distance and combined width of maxillary anterior teeth. Based on this study, interhamular notch distance is valuable and practicable for selection and arrangement of artificial anterior teeth. 
However, the result obtained from the study is not suggested as an exclusive and the most promising method for the selection of size of anterior teeth but as one of the supplement for the other available measures and methods for the selection of anterior teeth. Further studies should be conducted within Nepalese population with larger sample size to define an acceptable biometric ratio of such measurements for estimating width of maxillary anterior teeth.

\section{Conclusion}

Within the limitations of this study, the following conclusions can be drawn:

1. The mean combined width of six maxillary anterior teeth was $46.16 \pm 2.55 \mathrm{~mm}$.

2. The mean distance between right and left hamular notch was $41.0 \pm 2.87 \mathrm{~mm}$.

3. The mean value of ratio of combined width of maxillary anterior teeth and distance between right and left hamular notches was 1.13:1. There was a positive correlation between them and was statistically significant.

\section{References}

1. Patel J, Sethuraman R, Naveen Y, Shah MH. A comparative evaluation of the relationship of inner-canthal distance and inter-alar width to the inter-canine width amongst the Gujarati population. Journal of Advanced Oral Research 2011;2(3):31-38

2. Baker PS, Morris WJ, Lefebvre CA, Price GA, Looney SW. Relationship of denture cast measurements to width of maxillary anterior teeth. Journal of Prosthetic Dentistry 2011;105(1):44-50.

3. Park Y-S, Lee S-P, Paik K-S. The threedimensional relationship on a virtual model between the maxillary anterior teeth and incisive papilla. Journal of Prosthetic Dentistry 2007;98(4):312-18.
4. Petričević N, Katunarić M, Mehulić K, et al. Selection of appropriate artificial frontal teeth size using dimensions of hard palate. Collegium Antropologicum 2006;30(3):573-77.

5. Wong Chu Bing LLK, Zakiah Mohd isa. Incisive papilla ani hamular notches as guides to maxillary anterior teeth size in edentulous patients. Dentika Dental Journal, 2009;14(no.2):109-14.

6. Guldag MU, Büyükkaplan US, Sentut F, Ceylan G. Relationship between pterygomaxillary notches and maxillary anterior teeth. Journal of Prosthodontics 2010;19(3):231-34.

7. Scandrett FR, Kerber PE, Umrigar ZR. A clinical evaluation of techniques to determine the combined width of the maxillary anterior teeth and the maxillary central incisor. Journal of Prosthetic Dentistry 1982;48(1):15-22.

8. Zilberman O, Huggare JA, Parikakis KA. Evaluation of the validity of tooth size and arch width measurements using conventional and three-dimensional virtual orthodontic models. Angle Orthod 2003;73(3):301-6.

9. Riaz W, Aslam A, Javed MU, Azad AA. Selection of Appropriate Artificial Maxillary Central Incisor Size Using Dimensions of Hard Palate. Journal of Islamic International Medical College 2013:89.

10. Mavroskoufis F, Ritchie G. Variation in size and form between left and right maxillary central incisor teeth. Journal of Prosthetic Dentistry 1980;43(3):254-57.

11. Kini AY, Angadi GS. Biometric ratio in estimating widths of maxillary anterior teeth derived after correlating anthropometric measurements with dental measurements. Gerodontology 2013;30(2):105-11.

12. Sayed M, Porwal A, Al-Faraj N, Bajonaid A, Sumayli H. Evaluation of the Current Techniques and Introduction of a Novel Approach for Estimating Maxillary Anterior Teeth Dimensions. Journal of Contemporary Dental Practice 2017;18(7):541.

13. Petričević N, Čelebić A, Baučić M, Antonić R. Importance of hamular distance for calculation of the width of maxillary anterior teeth. Acta Stomatologica Croatica 2005;39(3):285-94. 